\title{
A VOCAÇÃO DO NOSSO TEMPO PARA A FILOSOFIA DO DIREITO... E PARA A FILOSOFIA DOS DIREITOS HUMANOS
}

\author{
THE VOCATION OF OUR TIME FOR THE PHILOSOPHY OF LAW... AND FOR THE PHILOSOPHY OF
}

HUMAN RIGHTS

Felipe Rodolfo de Carvalho*

Resumo:

Este ensaio objetiva responder à pergunta quanto ao papel da reflexão filosófica no âmbito do Direito e no âmbito dos Direitos Humanos, explicitando, antes de tudo, por que razão tal indagação necessariamente se coloca. A fim de apresentar uma resposta, busca distinguir as tarefas da Ciência Jurídica e da Filosofia do Direito, ressaltando, ao mesmo tempo, sua complementaridade. Por consequência, propõese a identificar não só papéis gerais da Filosofia do Direito, mas também seu papel específico diante do cenário jurídico contemporâneo. É aqui que a busca pelo sentido do Direito se coloca como incumbência da Jusfilosofia, encaminhando-a inexoravelmente para a temática dos Direitos Humanos, os quais demandam também ser ressignificados. Como conclusão, ressalta, então, a vocação do nosso tempo para a Filosofia do Direito e, correlatamente, para a Filosofia dos Direitos Humanos.

Palavras-chave: Direito. Crise do Direito. Filosofia do Direito. Filosofia dos Direitos Humanos. Vocação.

\begin{abstract}
:
This essay aims to answer the question about the role of philosophical critics in Law and Human Rights, spelling out, above all, why this inquiry necessarily arises. In order to present an answer, it seeks to distinguish the tasks of Legal Science and Philosophy of Law, underscoring its complementarity at the same time. It proposes to identify not only general roles of Philosophy of Law, but also its specific role in the contemporary legal scene. It is here that the search for the meaning of Law is placed as an incumbency of Philosophy of Law, inexorably directing to the Human Rights subject, which also needs to be redefined. As a conclusion, it highlights the vocation of our time to the Philosophy of Law and to the Philosophy of Human Rights.
\end{abstract}

Keywords: Law. Law Crisis. Philosophy of Law. Philosophy of Human Rights. Vocation. 
1. Por que Filosofia?

Filosofia. Filosofia do Direito. Filosofia dos Direitos Humanos... Estas são áreas do conhecimento pelas quais o jurista habitualmente não nutre muita admiração ou simpatia.

Colocada algumas vezes no primeiro semestre ou no primeiro ano do Curso de Direito, a disciplina de Filosofia do Direito costuma causar nos estudantes uma boa dose de irritação (FERRAZ JÚNIOR, 2004, p. 113).

Os alunos, que entram na Faculdade já impelidos a discutir questões concretas, casos jurídicos de vizinhos, lides familiares ou problemas normativos de dimensão nacional ou internacional, se deparam com um tipo de matéria que parece pouco ou nada ter a ver com o "Direito propriamente dito".

Estudar Filosofia se assemelha, à primeira vista, a se embrenhar num intricado conjunto de sistemas filosóficos complicados, que utilizam uma linguagem hermética, falam de assuntos ininteligíveis, colocam questões desnecessárias e apresentam soluções não só variadas, mas mutuamente discrepantes.

Estudar Filosofia, estudar Filosofia do Direito, estudar Filosofia dos Direitos Humanos, parece ser algo talvez até interessante para alguns, mas, para muitos, algo de muito pouco proveito prático. Arraigada na linguagem comum, ouve-se com frequência a repetida fórmula: "na teoria é uma coisa; na prática é outra".

Frases que tais, no fundo, acabam concorrendo para uma postura de preconceito e de desconfiança contra todo tipo de especulação filosófica.

Afinal: Por que Filosofia? Por que estudar Filosofia? Por que estudar Filosofia do Direito na Faculdade de Direito? Estas são perguntas que os alunos comumente levantam... Na verdade, não só os alunos, mas também certos professores, certos advogados, certos magistrados, certos membros do Ministério Público...

Já a pergunta "Por que estudar Filosofia dos Direitos Humanos?", esta pergunta raramente se faz... Talvez por desconhecimento de que haja não só uma Filosofia do Direito, mas também uma Filosofia dos Direitos Humanos, ou de que a própria Filosofia do Direito constitua, ao menos em parte, uma Filosofia dos Direitos Humanos.

De qualquer modo, poder-se-ia invocar a pergunta: Por que estudar Filosofia dos Direitos Humanos? Se é que é preciso estudar Filosofia dos Direitos Humanos, talvez fosse, então, também conveniente perguntar: Como deveríamos estudá-la? Como uma disciplina autônoma ou como um capitulo da disciplina de Filosofia do Direito? Mas como um capítulo da disciplina de Filosofia do Direito ou como um capítulo da disciplina de Direitos Humanos? 
O fato é que a reflexão filosófica no âmbito do Direito e dos Direitos Humanos gera controvérsia, provoca disputa, incita à discussão, desde logo, quanto à sua própria justificação e quanto à sua própria utilidade.

Mas, às vezes, quando perguntamos "Por que estudar Filosofia do Direito?" estamos, na realidade, querendo saber “Para que estudar Filosofia do Direito?”. Justificação e utilidade se confundem. Estudar Filosofia do Direito só parece ser justificável em termos de utilidade... Não haverá ela de ter alguma função?

É curioso notar que dificilmente a questão "Por que estudar Direito Constitucional, ou Direito Civil, ou Direito Penal etc.?" seja colocada... Os livros de Direito Constitucional, de Direito Civil, de Direito Penal etc. normalmente começam apresentando conceitos, discutindo naturezas jurídicas, expondo algum tipo de sumário histórico. A questão, porém, das razões pelas quais estudar uma ou outra disciplina específica do Direito não é colocada. Salvo, é claro, no caso do surgimento, por especialização, de novos ramos do conhecimento jurídico, a demandar, ao menos no início, algum tipo de discurso apologético...

Isto não acontece nos manuais de Filosofia do Direito... Por que não? Talvez em virtude da diferença mesma entre as disciplinas dogmáticas e as disciplinas zetéticas, estas capazes de questionar os seus próprios pressupostos, aquelas fadadas a tomá-los como inquestionáveis...2

De todo modo, uma vez que corrente no senso comum a ideia de que "Filosofia não serve para nada", torna-se, por conseguinte, necessário a quem quer que trabalhe com Filosofia do Direito ou a quem quer que ensine Filosofia do Direito responder às questões acerca do seu "Por que...?" e do seu "Para que...?"

No cerne das perguntas, não apenas uma ignorância acerca do papel da reflexão filosófica, mas, conjugada a ela, já uma certa desconsideração, para não falar num certo desprezo, em face do papel da reflexão filosófica.

Não obstante, as perguntas permanecem... É preciso respondê-las! Por que Filosofia do Direito? Para que Filosofia do Direito? Qual o papel da reflexão filosófica no âmbito do Direito? Ou ainda: Qual o papel da reflexão filosófica no âmbito do Direito e dos Direitos Humanos?

Em sua Introdução à Filosofia do Direito, Roscoe Pound, v. g., se pergunta, desde logo, no seu primeiro capítulo, sobre a função de tal disciplina. Cf. (POUND, 1965, p. 13-33).

2 Sobre a diferença entre dogmática e zetética, cf. (FERRAZ JÚNIOR, 2007, 39-51). 
2. O papel da reflexão filosófica no âmbito do Direito

Compreender o papel da reflexão filosófica no âmbito do Direito requer, antes de tudo, que se tenha em vista a diferença entre o que fazem a Filosofia do Direito e a Ciência Jurídica. ${ }^{3}$

\subsection{A Ciência Jurídica}

A Ciência Jurídica é também chamada de Ciência Dogmática do Direito. Deve-se o caráter dogmático da Ciência Jurídica à circunstância de partir de certos pressupostos assumidos como inquestionáveis. Ciência Dogmática do Direito, porque tem, na sua base, determinados dogmas que, por algum tipo de decisão, são postos fora de dúvida.

A Ciência Jurídica, ou Ciência Dogmática do Direito, pensa, deste modo, ex datis, isto é, a partir de "dados" tomados como irrefutáveis... Isto não significa que a Ciência Jurídica seja acrítica, ou, simplesmente, que, no seu interior, perguntas, ou questões, ou críticas, não possam ser formuladas... As indagações por elas realizadas são, porém, limitadas. Isto é: a problematização do Direito pela Ciência Jurídica está condicionada à utilização de argumentos imanentes ao Sistema Normativo. O Direito posto, o Direito vigente, remanesce, aí, de algum modo, intocado. Na ferida do Direito só se "toca", por assim dizer, a partir de dentro do Sistema Jurídico, não desde fora.

Não há problema algum em ser um cientista dogmático do Direito. Trata-se de uma postura legítima. Mais ainda: trata-se de uma postura indispensável. A Dogmática Jurídica, demonstrou-o Tercio Sampaio Ferraz Jr., tem sua função social. ${ }^{4}$

O Direito lida com problemas, com problemas que demandam solução. Espera-se do instrumento jurídico que seja capaz senão de gerar pacificação social ao menos de encerrar as polêmicas em torno de uma situação. A possibilidade de questionamento infinito poderia conduzir a um estado de paralisia, de irresolução, de perpetuação eterna dos problemas que esperam por respostas rápidas e eficientes, sob pena de prejuízos graves para o convívio social.

A tarefa do cientista do Direito de estabelecer condições para a dissolução jurídica das controvérsias humanas é, pois, essencial para a vida em sociedade. Em resultado, se, por um lado, carece de fundamento o preconceito do jurista contra o filósofo, por outro, é infundado o preconceito do filósofo contra o jurista. A atitude dogmática do

\footnotetext{
3 A distinção entre Ciência do Direito e Filosofia do Direito é com frequência invocada pelos autores preocupados em assinalar seus respectivos campos de investigação. Por todos, cf. (SICHES, 2008, p. 1-21).

4 Para mais aprofundamentos, cf. (FERRAZ JÚNIOR, 2015).
} 
jurista se torna perigosa apenas quando desaprecia, desvaloriza e desaconselha de todo a atitude filosófica, repudiando a propensão do espírito humano para a perquirição e para a irresignação diante do estabelecido.

\subsection{A Filosofia do Direito}

O que marca, então, a diferença entre a Ciência jurídica e a Filosofia do Direito? O que distingue uma e outra é a capacidade da Filosofia do Direito de superar, de transpor, de transcender os limites da Ciência Jurídica.

Justamente porque pode questionar infinitamente, é que a Filosofia do Direito, enquanto realização máxima do pensar, permite ir além dos quadrantes juscientíficos. A Filosofia, neste sentido, porque contestadora, é sempre crítica ${ }^{5}$ (cf. VILLEY, 2003, p. 31; REALE, 2007, p. 8; BITTAR; ALMEIDA, 2005, p. 19-23 e 50-52).

Se bem que filósofos do Direito e dogmáticos do Direito queiram com alguma frequência ser uns mais importantes do que outros, a distinção dos seus domínios não se dá em termos de maior ou menor importância, e, sim, de distintas, mas complementares, tarefas.

Se o papel da Ciência Dogmática do Direito é o de oferecer condições para a resolução jurídica dos problemas humanos, então qual é o papel da Filosofia do Direito?

Antes de responder, algumas considerações preliminares sobre a Filosofia do Direito merecem destaque.

Em primeiro lugar, enquanto a Ciência Jurídica tende para a especialização, a Filosofia do Direito conserva uma visão de unidade. O olhar filosófico é um olhar dirigido à totalidade. O Filósofo do Direito tende a ver o Direito no seu aspecto unitário, e não na especificidade das suas disciplinas dogmáticas: o Direito Constitucional, o Direito Civil, o Direito Penal, o Direito Administrativo, o Direito Tributário etc.

Depois, a preocupação com o alcance da totalidade torna a reflexão filosófica em torno do Direito uma atividade penosa: exige não só conhecimentos filosóficos como também conhecimentos jurídicos (cf. KAUFMANN, 2002, p. 25). Noutras palavras, aquele que adentra a Filosofia do Direito tem também de ser um bom dogmático do Direito, tem de conhecer suficientemente o Direito vigente. Não por outro motivo, em algumas Faculdades Jurídicas opta-se por alocar a disciplina jusfilosófica entre o meio e o fim do curso.

\footnotetext{
5 A preocupação com o aspecto crítico da Filosofia do Direito é destacada, entre outros, por Eduardo C. B. Bittar (2007) e Luis Alberto Warat e Albano Marcos Bastos Pêpe (1996), influenciados pela tradição filosófica legada pela chamada "Escola de Frankfurt".
} 
Finalmente, preponderantemente, a Filosofia do Direito se realiza, segundo apontamento de Norberto Bobbio, muito mais por juristas com interesses filosóficos do que por filósofos com interesses jurídicos (cf. TROPER, 2008, p. 17-20). É natural que assim o seja. O perigo disto, porém, é a transformação da Filosofia do Direito em mera Teoria Geral do Direito, ou, ainda, a recaída num puro cientificismo positivista que, partindo da experiência jurídica, desconsidera os conhecimentos filosóficos. Transformada a Filosofia do Direito em Filosofia exclusiva dos juristas, desapegados do rigor filosófico, o que se tem, no máximo, é uma filosofia jurídica vulgar, em cuja centralidade aparece a figura pejorativa do "jurista metido a filósofo" ... que pouco faz senão esguichar aleatoriamente citações alheias...

\subsection{A Filosofia do Direito e seus papéis}

Diante de tais considerações, à pergunta acerca do papel da reflexão filosófica no âmbito do Direito, convém sublinhar, antes de mais, a inexistência de um consenso sobre sua resposta (cf. TROPER, 2008, p. 13). Em todo caso, visto que curiosa e indagadora, a Filosofia do Direito conserva, indubitavelmente, os papeis de compreensão e de crítica do Direito. Dada, porém, a sua capacidade de compreender e de exercer juízos carregados de criticidade sobre o fenômeno jurídico, outro papel da Filosofia do Direito ainda se descortina correlatamente: o de vigilância histórica. Diz-se, assim, que a ela compete manter-se de olhos abertos e acesos para a teoria e a prática jurídicas, nas suas cambiantes manifestações (cf. BITTAR; ALMEIDA, 2005, p. 50-52).

Enquanto incumbida de uma missão vigilante, a Filosofia do Direito não pode passar ao largo dos problemas do seu tempo, ignorando as questões do momento. $\mathrm{O}$ contato, todavia, com a realidade presente suscita, no interior da Jusfilosofia, a atualização dos seus problemas e o deslindamento de novos papéis.

Noutras palavras, cada conjuntura histórica traz para a Filosofia em geral, e para a Filosofia do Direito em particular, novas questões ou as recoloca sob novas perspectivas. Em resultado, a tarefa da Filosofia se amolda, pois, ao tempo, se perfazendo e se refazendo na circunstancialidade da experiência epocal humana.

Desta forma, se se pode dizer que a reflexão filosófica não contém, por natureza, um compromisso imediato com a ação, isto não faz dela, contudo, uma espécie de exercício especulativo irresponsável.

Há, neste sentido, um dever de atualidade que acompanha, necessariamente, a Filosofia do Direito: é seu direito, mas também seu dever, atentar-se para a realidade atual do Direito.

Deste modo, talvez o mais apropriado consista, antes, em saber o papel da reflexão filosófica no âmbito do Direito nos dias de hoje. 


\subsection{O papel da Filosofia do Direito hoje}

Do mundo atual diz-se muitas coisas. Os diagnósticos, no entanto, parecem apontar para um cenário de esfacelamento do projeto moderno-iluminista, marcado pela ideia de ordem, de disciplina, de progresso, de racionalização etc. O mundo atual é um mundo desbussolado... desorientado... sem referências... Nele, o homem se sente perdido... sem sentido... abandonado... Trata-se do mundo desregulamentado, liberalizado, flexibilizado, fluido, descontrolado da "pós-modernidade" (LYOTARD, 2009) ou da "modernidade líquida" (BAUMAN, 2001). É o mundo no interior do qual não há mais padrões fortes, códigos unívocos, regras rígidas nos quais seja possível assentar a própria ação. É o mundo da agonia, do desassossego, da incerteza, do tédio, da angústia, do medo...

Neste contexto, assiste-se a um processo de degeneração filosófica, em que a Filosofia, tornada filosofia, se torna cada vez mais predisposta a assumir a forma de uma filosofia do espetáculo: filosofia de exibição, filosofia de fachada, filosofia de vitrine... Isto é: uma filosofia barata, filosofia que escarnece do pensamento filosófico, que faz caricatura dos filósofos. O que caracteriza aquilo que se pode chamar, com alguma liberdade, de "filosofia de espetáculo" não é tanto a falta de rigor e de adequação com que seus "filósofos" colocam suas perguntas, mas o seu oferecimento fácil de respostas. É na contextura de uma sociedade espetacular e consumista que a Filosofia sem dificuldades se degenera em autoajuda. Para uma tal "filosofia do espetáculo", o que importa propriamente não são as perguntas que se fazem, mas as respostas prontas, pré-fabricadas, que se produzem para o consumo nunca acabado das pessoas. De "comentaristas" de programas de televisão, como telejornais, os "filósofos" descambam também para a condição de profissionais do entretenimento, sua função consistindo em fornecer guias “confiáveis" para ação, se possível com alguma dose de humor.

Enquanto momento de esfacelamento dos ideais modernos, a modernidade se encontra ela mesma em crise. Consigo, no entanto, arrasta todos os bastiões que erguera como fundamentais para a realização do seu projeto. Como consequência, é também o Direito moderno, fundado na lei, alicerçado na autoridade do Estado, dirigido à salvaguarda dos interesses individuais, que deságua num estado crítico. Vive-se uma crise do Direito.

É a desorientação do mundo contemporâneo atingindo também o fenômeno jurídico, que passa por uma crise de eficácia do seu ordenamento jurídico como um todo (cf. BITTAR, 2009, p. 184-214), resultante de fatores como: a) tempo jurídico acelerado: observa-se uma mutabilidade jurídica desenfreada pela proliferação caótica de leis,

Com licença filosófica, a expressão é tomada de empréstimo de Guy Debord, autor da famosa obra La société du spectacle, e de Mario Vargas Llosa, que lhe dá conotação própria em La civilización del espectáculo. 
produzidas ao sabor dos instantes, para durarem apenas enquanto persistirem certos interesses; b) incapacidade do Direito de integrar a sociedade: as normas jurídicas já não conseguem regular suficientemente a convivência humana, com a consequente perda do seu prestígio; c) Ciência Jurídica especializada e incapaz de racionalizar suficientemente o Direito: além de uma multiplicação de disciplinas jurídicas, nota-se que o trabalho dos juristas de sistematização do material normativo cai em qualidade, passando-se de um "Direito sistematizado" para um "Direito esquematizado", em que a antiga busca de um "Direito simples" se degenera no contentamento com um "Direito simplificado"; isto, para não falar do ainda reinante insulamento disciplinar, da cegueira perante a totalidade e a realidade...; d) ensino jurídico operatório: as Faculdades não formam juristas, mas operadores do Direito, que enxergam nas obras jurídicas apenas manuais de instrução... Os livros jurídicos se tornam meros objetos de uso, descartáveis, e os seus leitores, meros consumidores de informação... Nesta ambiência, o Professor de Direito ou é um ídolo a quem não se faz perguntas, ou um mero contratado de quem se exige não ensinamento, apenas o repasse de conhecimentos privilegiados; e) prática jurídica afetada por interesses extrajurídicos: toma-se consciência de que o Direito se submete aos influxos de agentes econômicos, de grupos de pressão, de acertos de favores, de negócios escusos, de vantagens pessoais, de impactos emocionais etc. (cf. CARVALHO, 2017, p. 200-217).

A consciência de crise do Direito, do fracasso do Direito enquanto empreendimento humano, da capacidade do Direito de se aliar às piores e mais horrorosas pretensões (a exemplo do sistema jurídico nazista), conduz o Direito a um momento de “questionabilidade última" (KAUFMANN, 2002, p. 41).

$\mathrm{O}$ jurista que tem alguma consciência da realidade do Direito do século XX para cá tem de inevitavelmente estar com a consciência pesada... Para invocar Castanheira Neves (2012), é a pergunta pelo sentido do Direito que se coloca em última instância: $O$ Direito hoje e com que sentido? O Direito, hoje, parece carecer de orientação, de norte, de direção...

Esta situação de carência ou perda de sentido do Direito é resultado, entre outros fatores, da vitória até pouco tempo, no domínio jurídico, do formalismo. O predomínio de uma racionalidade formal com relação a fins que despreza uma racionalidade substantiva, baseada em valores, conduz o Direito a uma situação de vazio... O Direito resta suspenso no vazio... Sabe-se bem a que levou o positivismo jurídico...

Não se pode deixar de reconhecer que, para o processo de perda de sentido do Direito, a Ciência Jurídica desempenhou um papel de destaque. É que a Ciência Jurídica, tradicionalmente, como o próprio Kelsen reconheceu, tem um papel apenas descritivo da realidade jurídica (KELSEN, 2015, p. 80-84). Naturalmente, as coisas não são tão simples assim. A Ciência Jurídica não só informa o Direito, mas também o conforma. Não há, deste modo, apenas descrição na atividade juscientífica; há já direção 
do comportamento (vide FERRAZ JÚNIOR, 2007, p. $83-91$ e 2014, p. 5-10). De toda forma, a preocupação da Ciência Jurídica é a de dizer acerca de um determinado Direito vigente, é a de fazer referência ao Direito aplicável num contexto de certo povo e de certa época. A Ciência Jurídica não se pergunta sobre "O que é o Direito em si?" Esta é uma questão eminentemente filosófica (cf. DEL VECCHIO, 1979, p. 304-305; VILLEY, 2003, p. 15-16). A questão da definição do Direito suscita, concomitantemente, a questão do sentido do Direito. O Direito não há de estar orientado numa direção?

A Ciência Jurídica pode, assim, até explicar o modo de funcionamento do Direito vigente, oferecendo as condições necessárias para que os profissionais resolvam os casos que pedem por solução. Isto, porém, não faz dela capaz de oferecer um sentido para o Direito. ${ }^{7}$ Explicar não se confunde com dar ou encontrar um sentido...

Max Weber chamou o processo de retirada de sentido do mundo pela Ciência de desencantamento... ${ }^{8} \mathrm{O}$ sociólogo tinha em mente as ciências empíricas modernas. Talvez, contudo, o mesmo processo possa ser notado no âmbito da Ciência Jurídica. O olhar de quem enxerga o Direito apenas pela viseira juscientífica é um olhar desencantado... de quem consegue explicá-lo, mas de quem não consegue encontrar para ele um sentido... A Ciência Jurídica desencanta o Direito: despoja-o do seu sentido. Como, então, localizá-lo?

Se não se quiser apelar a explicações religiosas, a procura pelo sentido do Direito deve se dar, hoje, no plano filosófico. A Jusfilosofia pode, é certo, desvirtuandose da sua própria missão, resignar-se a um papel de legitimação reflexiva de um estado jurídico de coisas, recusando, por consequência, todo seu potencial contestatório (cf. NEVES, 2003, p. 40-141). Ela pode, no entanto, identificar neste momento histórico decisivo para o destino do Direito a ocasião propícia para se questionar sobre o seu problema significativo.

O próprio jurista que lida com o Direito contemporâneo parece ser submetido a uma espécie de alternativa: ou a opção pela resignação ao status quo, pela ignorância da realidade frágil e desorientada do Direito, pelo refúgio no agir automático da tecnologia jurídica que dele faz um dente de engrenagem; ou a opção pelo exercício filosófico capaz de compreensão, de crítica e de vigilância, mas também de busca de sentido.

Em termos semelhantes, Immanuel Kant já alertava: "Tal como a muito citada indagação ‘o que é a verdade’, a questão 'o que é direito?' poderia certamente embaraçar o jurista, se este não quiser cair numa tautologia ou, ao invés de apresentar uma solução universal, aludir ao que as leis em algum país em alguma época prescreveram. Ele pode realmente enunciar o que é estabelecido como direito (quid sit iuris), ou seja, aquilo que as leis num certo lugar e num certo tempo dizem ou disseram. Mas se o que essas leis prescreviam é também direito e qual o critério universal pelo qual se pudesse reconhecer o certo e o errado (iustum et iniustum), isto permaneceria oculto a ele (...)". (KANT, 2008, p. 75-76).

8 Sobre o conceito weberiano de "desencantamento", cf., especialmente, (WEBER, 2016, p. 655 e ss.); (PIERUCCI, 2003, p. 150-166) e (NOBRE, 2008, p. 286-290). 
Hoje, o papel da Jusfilosofia parece, então, consistir em colocar o problema do Direito sob novas bases. Compete a ela re-pensar o Direito, buscando para ele um referencial indisponível, capaz de apontar, de algum modo, onde ele começa e onde ele termina. A procura pelo sentido do Direito envolve, por conseguinte, uma procura pelos seus fundamentos e pelos seus fins (cf. VILLEY, 2003, p. 7). Mas onde, afinal, encontrarse-ia este vetor diretivo do fenômeno jurídico, para o qual a Filosofia do Direito deve encaminhar suas reflexões?

3. O papel da reflexão filosófica do âmbito do Direito... e dos Direitos Humanos

Os Direitos Humanos talvez constituam, hoje, este referencial indisponível, este norte perdido que é, no entanto, procurado... Neles, pode-se constatar uma terceira via ressignificativa do Direito que não recai no encanecido debate positivismo versus jusnaturalismo.

É que, mesmo quando positivados na Constituição, transformando-se em direitos fundamentais, parecem conservar uma natureza diferenciada em face dos demais direitos positivos. Jürgen Habermas refere-se a eles enquanto uma "utopia realista", ao cunhar a expressão Utopia Realista dos Direitos Humanos. ${ }^{9}$ Curiosa, a expressão não poderia ser mais adequada. Com ela, enfatiza-se o fato de que são uma utopia, um alvo a que se almeja atingir, mas se trata de uma utopia real, objetivada ou plasmada em documentos jurídicos.

Pode-se acrescentar que a ideia de uma "u-topia" remete a algo como o "não-lugar" dos Direitos Humanos. Eles estão e não-estão no Direito. Topos remete a "lugar". "U-tópico" é, assim, aquilo que não tem lugar, que não se localiza, que ao menos não se assenta definitivamente.

Ora, mesmo que tornados direitos positivos, isto é, conquanto positivados, os Direitos Humanos expressam, em face do ordenamento jurídico, uma transcendência a partir de dentro, isto é, "uma espécie de enclave para-dentro e para-fora de si mesmo" (DERRIDA, 2015, p. 101). Por intermédio dos Direitos Humanos, uma transcendência ética adentra a imanência do Direito. Enquanto concretização da Ética no Direito, os Direitos Humanos materializam um "enclave da transcendência", uma "inclusão do excesso", uma "transcendência na imanência" (DERRIDA, 2015, p. 117). Transcendência, em todo caso, que só pode vir à tona a partir da imanência de uma condição histórica inter-

\footnotetext{
9 "Os direitos humanos formam uma utopia realista na medida em que não mais projetam a imagem decalcada da utopia social de uma felicidade coletiva; antes, eles ancoram o próprio objetivo ideal de uma sociedade justa nas instituições de um Estado constitucional.” (HABERMAS, 2012, p. 31).
} 
humana: “(...) encontram-se na história e são produto dela e, ao mesmo tempo, situam-se fora da história e participam de seu julgamento" (DOUZINAS, 2009, p. 359).

Numa benfazeja alternância de sua condição, que oscila entre o dentro e o fora, os Direitos Humanos operam ora como elemento de unidade do ordenamento ora como elemento de abertura do ordenamento: fundam uma ordem jurídica, mas também a criticam. Erigem, por conseguinte, uma ordem jurídica ao mesmo tempo em que inauguram o seu julgamento, tornando possível a sua transformação: denunciam as injustiças praticadas em nome do Direito, apontando já para uma Justiça carente de realização. Desta forma, os Direitos Humanos se colocam como ponto de partida mas também como ponto de chegada do Direito. Deles se parte e para eles se dirige. Fundando-se nos Direitos Humanos, o Direito caminha no sentido da efetivação dos Direitos Humanos.

Tudo isto aponta para o fato de que, neste seu papel de busca pelo sentido do Direito, a Filosofia Jurídica se encaminha, na atualidade, inexoravelmente para o tema dos Direitos Humanos.

É, por assim dizer, a própria discussão quanto ao sentido do Direito que conduz ao problema dos Direitos Humanos. O Direito que se desconecta da proteção da pessoa, ao deixar de reconhecer a todos e a cada um os seus direitos mais básicos, não perde o seu referencial ético necessário?

Mas se pode, agora, perguntar: O que são os Direitos Humanos? Não expressam eles próprios um sentido singular? Será que é possível concordar integralmente com a opinião de Norberto Bobbio, para quem "o problema dos Direitos Humanos, hoje, não é tanto o de justificá-los, mas o de protegê-los”? (BOBBIO, 2004, p. 16).

$\mathrm{O}$ consenso internacional quanto à necessidade de proteger os Direitos Humanos não parece ser suficiente para colocar o problema do seu sentido em segundo plano... Se não se atenta ao sentido dos Direitos Humanos, ao seu fundamento e ao seu fim, perde-se uma orientação segura sobre como utilizá-los. Em nome dos Direitos Humanos, pode-se fazer muitas coisas... inclusive violar Direitos Humanos... Feitos fórmula fácil de dourar discursos, objeto de consenso presumido, mas de sentido vazio, os Direitos Humanos podem ser utilizados para as mais distintas pretensões, das mais honestas às mais tenebrosas (cf. CARVALHO, 2017, p. 287-303; COMPARATO, 2018, p. 8-10).

Isto se agrava quando se atenta para realidades, como a brasileira, onde se assistem a movimentos de rejeição ou de desqualificação dos Direitos Humanos, cujos discursos se assentam em generalizações de estereótipos que contribuem para a sua deslegitimação... Para lidar com esta situação, a pergunta pelo sentido dos Direitos Humanos também tem relevância, a fim de se eliminar confusões e equivocadas assimilações (cf. CALDEIRA, 1991). 
Se a pergunta pelo sentido importa, então a Filosofia do Direito, hoje, há também de se endereçar para uma Filosofia dos Direitos Humanos... A Filosofia do Direito, na atualidade, há de chegar ao problema dos Direitos Humanos... Debruçando-se sobre o Direito, a reflexão jusfilosófica hodierna é como que convocada, inevitavelmente, a abordar o tema dos Direitos Humanos, como se tratasse daquele tipo de questão da qual não se pode passar ao largo sem nenhuma consequência grave para a reflexão como um todo.

\section{A Filosofia como vocação do nosso tempo}

Não se pode, apesar de tudo, fazer um elogio leviano da Filosofia. Há, de fato, momentos em que fazer Filosofia do Direito é uma impertinência, ou até mesmo uma imprudência, ou até mesmo uma indecência... ${ }^{10}$ Situações há em que o que se demanda é um agir sobre o mundo: agir rápido, consequente e eficiente... Imprescindível é, sim, fazer as questões certas, mas imprescindível é também fazer as questões certas nos momentos certos. Momentos há em que é preciso parar de perguntar! [O filósofo é como aquele aluno "chato e atrevido" que faz perguntas, talvez "mil" perguntas, em sala de aula. Ele é importantíssimo. Horas há, contudo, em que o exercício demasiado do direito de perguntar atravanca o progresso da aula.] Situações existem, portanto, em que o que se requer é uma suspensão provisória do pensar em favor do agir...

A Filosofia, no entanto, é sempre uma espécie de parada. Para-se para pensar! O pensamento interrompe o agir imediato sobre o mundo. Esta interrupção às vezes se faz necessária, porque, sem ela, não é possível superar o hábito que enrijece o pensamento e entorpece a ação.

De maneira geral, o profissional do Direito é um ocupado: não tem tempo para o tipo de reflexão que é a reflexão filosófica (cf. VILLEY, 2003, p. 16). Não é que o filósofo do Direito seja um desocupado; pelo contrário, predispôs-se a fazer da reflexão do Direito sua própria ocupação, mesmo quando a assume numa perspectiva preponderantemente prática. Este momento de "parada", de concentração reflexiva, é, em todo caso, conditio sine qua non do exercício filosófico. O jurista, se não pretende ser ignorante dos pressupostos que sustentam teoricamente sua ação, isto é, se pretende ser mais do que operador de uma maquinaria jurídica contemporânea impregnada de avarias, precisa suspender por alguns instantes sua atividade prática cotidiana. Nada pior, em termos de Ética ou Filosofia Moral, do que a ação desligada dos seus adequados fundamentos orientadores...

10 Emmanuel Lévinas afirmava em 1938: "Existem momentos em que a Filosofia é uma inconveniência." (LÉVINAS, 2006, p. 152). 
Isto não quer dizer que devam todos se tornar filósofos do Direito. Ao menos não mais podem, porém, ignorar os pressupostos filosóficos que sustentam a Ciência Jurídica com a qual trabalham. Uma reflexão filosófica mínima constitui uma sua espécie de poder-dever: não só uma prerrogativa mas também uma exigência inarredável.

$\mathrm{O}$ fato é que vivemos uma crise do Direito que se manifesta enquanto uma crise de orientação, uma crise de direção, uma crise de sentido. Esta situação de crise significativa do Direito parece reacender no espírito humano sua vocação para a reflexão filosófica. Costuma-se dizer, aliás, que filosofar, refletir filosoficamente, não se consubstancia num mero exercício ocioso ou estéril, mas numa vocação intrínseca e constante do espírito humano (cf. DEL VECCHIO, 1979, p. 309; VILLEY, 2003, p. 27).

Uma ambivalência certamente marca a situação jurídica contemporânea: de um lado, um processo continuado de tecnificação extrema do Direito; de outro, uma abertura de espaços para a interrogação do Direito, inclusive para a sua interrogação ética (TROPER, 2008, p. 30). Nesta situação dilemática do Direito, o jurista também é posto diante de uma alternativa: se não quer ser um autômato, é chamado a pensar. O brado de Kant ainda ressoa: Sapere aude!

Num texto de 1962, Miguel Reale se referia a um "chamado vivo para a Filosofia do Direito". Seu alerta, que retomava, de maneira adaptada, fórmula contida em conhecido opúsculo de Savigny (2002), era expresso sobre a "vocação de nosso tempo para a Filosofia do Direito". A fim de superar a situação de crise jurídica já encetada, deixava claro ser preciso que o trabalho de Ciência Jurídica não mais se apartasse do trabalho da Filosofia do Direito (cf. REALE, 1962, p. 90, 95 e 112).

Este alerta e esta sugestão permanecem atualíssimos, com o acréscimo de que o chamado se estende, hoje, também, para a Filosofia dos Direitos Humanos. De modo que não é possível lidar com o Direito sem resvalar para a discussão do seu sentido que é dado pelos Direitos Humanos, também carentes de ressignificação filosófica.

Cuiabá, abril de 2018.

\section{Referências}

BAUMAN, Zygmunt. Modernidade líquida. Tradução de Plínio Dentzien. Rio de Janeiro: Jorge Zahar, 2001.

BIELEFELDT, Heiner. Filosofia dos direitos humanos: fundamentos de um ethos de liberdade universal. Tradução de Dankwart Bernsmüller. São Leopoldo: Ed. Unisinos, 2000.

BITTAR, Eduardo C. B. Filosofia crítica e filosofia do direito: por uma filosofia social do direito. Revista Cult, São Paulo, v. 112, p. 53-55, 2007. Disponível em: < https://revistacult.uol.com.br/ 
home/filosofia-critica-e-filosofia-do-direito-por-uma-filosofia-social-do-direito/> Acesso em: 13 set. 2017.

. O Direito na pós-modernidade e reflexões frankfurtianas. 2. ed. rev., atual. e ampl. Rio de Janeiro: Forense Universitária, 2009.

BITTAR, Eduardo C. B.; ALMEIDA, Guilherme de Assis. Curso de filosofia do direito. 4. ed. São Paulo: Atlas, 2005.

BOBBIO, Norberto. A era dos direitos. Tradução de Carlos Nelson Coutinho. Rio de Janeiro: Elsevier, 2004.

CALDEIRA, Teresa Pires do Rio. Direitos humanos ou "privilégios de bandidos"? Desventuras da democratização brasileira. Novos Estudos - CEBRAP, São Paulo, n. 30, p. 162-174, jul. 1991.

CARVALHO, Felipe Rodolfo de. Outramente: o direito interpelado pelo rosto do outro. 2017. 461f. Tese (Doutorado) - Faculdade de Direito, Universidade de São Paulo, São Paulo, 2017.

COMPARATO, Fábio Konder. Direitos humanos no Brasil: o passado e o futuro. Revista USP, São Paulo, n. 43, p. 168-175, set./nov. 1999.

. Fundamento dos direitos humanos. São Paulo: Instituto de Estudos Avançados da Universidade de São Paulo, 1997. Disponível em: <http://www.dhnet.org.br/direitos/anthist/a_pdf/ comparato_fundamentos_dh.pdf $>$. Acesso em: 2 fev. 2018.

CUNHA, Paulo Ferreira da. Filosofia jurídica prática. Belo Horizonte: Fórum, 2009. Resenha de: LAUAND, Luiz Jean. Paulo Ferreira da Cunha: filosofia jurídica prática. Notandum, ano 13, n. 22 , p. 51-52, jan./abr. 2010.

DEL VECCHIO, Giorgio. Lições de filosofia do direito. Tradução de António José Brandão. 5 ed. cor. e atual. Coimbra: Arménio Amado, 1979.

DERRIDA, Jacques. Adeus a Emmanuel Lévinas. Tradução de Fábio Landa com a colaboração de Eva Landa. São Paulo: Perspectiva, 2015.

DOUZINAS, Costas. O fim dos direitos humanos. Tradução de Luzia Araújo. Porto Alegre: Unisinos, 2009.

FERRAZ JÚNIOR, Tércio Sampaio. A ciência do direito. 3. ed. São Paulo: Atlas, 2014.

. A trivialização dos direitos humanos. Novos Estudos - CEBRAP, São Paulo, n. 28, p. 99115, out. 1990 .

. Estudos de filosofia do direito: reflexões sobre o poder, a liberdade, a justiça e o direito. 3. ed. São Paulo: Atlas, 2009.

. Filosofia do Direito: do perguntador infantil ao neurótico filosofante. In: ALVES, Alaôr Caffé et al. O que é a filosofia do direito? Barueri, SP: Manole, 2004.

. Função social da dogmática jurídica. 2. ed. São Paulo: Atlas, 2015. 
FERRAZ JÚNIOR, Tércio Sampaio. Introdução ao estudo do direito: técnica, decisão, dominação. 5. ed. rev. e ampl. São Paulo: Atlas. 2007.

HABERMAS, Jürgen. O conceito de dignidade humana e a utopia realista dos direitos humanos. In: . Sobre a constituição da Europa. Tradução de Denilson Luis Werle, Luiz Repa e Rúrion Melo. São Paulo: Unesp, 2012. p. 7-37.

KANT, Immanuel. A metafísica dos costumes. Tradução de Edson Bini. 2. ed. rev. São Paulo: EDIPRO, 2008.

KAUFMANN, Arthur. Filosofia do direito, teoria do direito, dogmática jurídica. In: KAUFMANN, Arthur; HASSEMER, Winfried (Org.). Introdução à filosofia do direito e à teoria do direito contemporâneas. Tradução de Marcos Keel e Manuel Seca de Oliveira. Lisboa: Fundação Caouste Gulbenkian, 2002.

KELSEN, Hans. Teoria pura do direito. Tradução de João Baptista Machado. 8. ed., 5. tiragem. São Paulo: WMF Martins Fontes, 2015.

LÉVINAS, Emmanuel. L'essence spirituelle de l'antisémitisme (d'après Jacques Maritain). In: CHALIER, Catherine; ABENSOUR, Miguel (Org.). Cahier de L'Herne: Emmanuel Lévinas. Paris: LGF, 2006.

LYOTARD, Jean-François. A condição pós-moderna. Tradução de Ricardo Corrêa Barbosa. 12. ed. Rio de Janeiro: José Olympio, 2009.

NEVES, António Castanheira. A crise actual da filosofia do direito no contexto da crise global da filosofia: tópicos para a possibilidade de uma reflexiva reabilitação. Coimbra: Coimbra Editora, 2003.

. O direito hoje e com que sentido? O problema atual da autonomia do direito. 3. ed. Lisboa: Piaget, 2012.

NINO, Carlos Santiago. Ética y derechos humanos: un ensayo de fundamentación. 2. ed. ampl. y rev. Buenos Aires: Astrea, 1989.

NOBRE, Marcos. Weber: racionalização e desencantamento do mundo. In: NOBRE, Marcos (Org.). Curso livre de teoria crítica. Campinas: Papirus, 2008.

PIERUCCI, Antônio Flávio de Oliveira. O desencantamento do mundo: todos os passos do conceito em Max Weber. São Paulo: Editora 34, 2003.

POUND, Roscoe. Introdução à filosofia do direito. Tradução de Álvaro Cabral. Rio de Janeiro: Zahar, 1965.

REALE, Miguel. A filosofia do direito e as formas do conhecimento jurídico. Revista da Faculdade de Direito da Universidade de São Paulo, São Paulo, v. 57, p. 90-112, jan./dez. 1962.

. Filosofia do direito. 20. ed. São Paulo: Saraiva, 2017. 
REALE, Miguel. Introdução à filosofia. 4. ed. São Paulo: Saraiva, 2007.

SAVIGNY, Friedrich Carl von. Da vocação do nosso tempo para a legislação e a jurisprudência. In: MORRIS, Clarence (Org.). Os grandes filósofos do direito: leituras escolhidas em direito. Tradução de Reinaldo Guarany. São Paulo: Martins Fontes, 2002.

SICHES, Luis Recaséns. Tratado general de filosofia del derecho. 19 ed. México: Porrúa Editorial, 2008.

TROPER, Michel. A filosofia do direito. Tradução de Ana Deiró. São Paulo: Martins Fontes, 2008.

VILLEY, Michel. Filosofia do direito: definições e fins do direito: os meios do direito. Tradução de Márcia Valéria Martinez de Aguiar. São Paulo: Martins Fontes, 2003.

. O direito e os direitos humanos. Tradução de Maria Ermantina de Almeida Prado Galvão.

São Paulo: WMF Martins Fontes, 2007.

WARAT, Luis Alberto; PÊPE, Albano Marcos Bastos. Filosofia do direito: uma introdução crítica. São Paulo: Moderna, 1996.

WEBER, Max. A ciência como vocação. In: . Metodologia das ciências sociais. Tradução de Augustin Wernet. 5. ed. São Paulo: Cortez; Campinas: EDUNICAMP, 2016. 